\title{
High-Voltage Converter for the Traction Application
}

\author{
Sergey Volskiy, ${ }^{1}$ Yury Skorokhod, ${ }^{2}$ and Dmitriy Sorokin ${ }^{2}$ \\ ${ }^{1}$ Moscow Aviation Institute (National Research University), Volokolamskoe Shosse 4, A-80, GSP-3, Moscow 125993, Russia \\ ${ }^{2} J o i n t-S t o c k$ Company "Transconverter", Malaya Kaluzhskaya Street 15/17, Moscow 119071, Russia \\ Correspondence should be addressed to Yury Skorokhod; skorohod@transconverter.ru
}

Received 28 March 2016; Accepted 29 May 2016

Academic Editor: Pavol Bauer

Copyright (C) 2016 Sergey Volskiy et al. This is an open access article distributed under the Creative Commons Attribution License, which permits unrestricted use, distribution, and reproduction in any medium, provided the original work is properly cited.

\begin{abstract}
High-voltage converter employing IGCT switches $\left(V_{\mathrm{DC}}=2800 \mathrm{~V}\right)$ for traction application is presented. Such a power traction drive operates with an unstable input voltage over $2000 \cdots 4000 \mathrm{~V}$ DC and with an output power up to $1200 \mathrm{~kW}$. The original power circuit of the high-voltage converter is demonstrated. Development of the attractive approach to designing the low-loss snubber circuits of the high-frequency IGCT switches is proposed. It is established on the complex multilevel analysis of the transient phenomena and power losses. The essential characteristics of the critical parameters under transient modes and the relation between the snubber circuit parameters and the losses are discussed. Experimental results for the prototype demonstrate the properties of new power circuit. The test results confirm the proposed high-voltage converter performance capability as well as verifying the suitability of the conception for its use in the Russian suburban train power system and other high-voltage applications.
\end{abstract}

\section{Introduction}

Nowadays, most suburban trains in Russia have 2 head carriages, 5 or 6 motor carriages, and 3 or 4 auxiliary carriages [1]. Thus suburban train consists from 10 or 12 carriages. The traction driver is mounted at every second van of the train. It has nominal output power of $1200 \mathrm{~kW}$ at the unstable supply voltage $\left(U_{s}=2000 \cdots 4000 \mathrm{~V} \mathrm{DC}\right)$ in the contact network. Each traction drive supplies 4 brushed electric DC motors, which are connected in series. Used DC motors have a rated voltage of $750 \mathrm{~V} \mathrm{DC}$ and nominal power of $250 \mathrm{~kW}$.

Each traction drive contains contactor equipment and 18-item power circuit breakers and power starting resistors, which carry out start-up and regulation of the train speed. Numerous efforts to use semiconductor power traction drive instead of obsolete and unserviceable 18-item power circuit breakers with power starting resistors were not successful.

The difficulties of designing semiconductor power highvoltage converter for suburban trains in Russia are the following:

(i) The wide range of input voltages (from $2000 \mathrm{~V}$ up to 4000 V DC) with possible short single impulses up to $5000 \mathrm{~V} \mathrm{DC}$ and with duration up to $10 \mathrm{~ms}$. (ii) The wide range of environment temperature (from minus $50^{\circ} \mathrm{C}$ up to plus $45^{\circ} \mathrm{C}$ ) and presence of high humidity, frost, and hoarfrost.

(iii) The absence of high-frequency high-voltage power semiconductor devices and capacitors and other elements, which are required to solve these problems.

It is known that using the high-frequency principle of the electrical energy transformation is an effective and attractive mean for the power converters. It provides the advantage of reducing their weight, sizes, and cost. However, the use of high operating frequency for the power converters leads to the number of simultaneous problems. The important problem is related to the defence circuits of the power switches where the power losses are increasing in conformity with the frequency rise.

It should be noted that total losses in defence circuits for the converters of the Russian suburban trains are much higher because of the high supply voltage $2000 \cdots 4000$ V DC [2-4]. Owing to this high-voltage level the power losses are increasing $10 \cdots 30$ times in comparison with supply voltage 750 V DC or 1500 V DC.

Thus, the development of the defence circuits in such converter application is prime importance. Thereto, during the design process of defence circuits design, it is necessary 
to solve two conflicting problems. The first one is to provide normal operation for the semiconductor devices and could be solved by increasing of the components of the snubber circuit. The second problem is to minimize the losses in the protection circuit and should be solved by reducing the values of the parameters of the snubber circuit. The authors suggest a compromise solution of these problems.

Thus the described difficulties in designing a power traction drive require unusual approaches and decisions in designing high-voltage converter as a system, as well as in choosing power device and snubber circuits, control systems, and so forth. In this paper the authors are offered new power high-voltage high-frequency converter for traction drive employing IGCT switches $\left(V_{\mathrm{DC}}=2800 \mathrm{~V}\right)$.

\section{The Power Circuit of the Proposed High-Voltage Converter}

As noted, the required output power of the high-voltage converter is $1200 \mathrm{~kW}$. However the maximum power of the traction drive, which is equal to the multiplication of the peak current after the input smoothing filter and maximum input voltage, must be not less than $1700 \mathrm{~kW}$ because of the wide range of voltages in the contact network (from $2000 \mathrm{~V}$ up to $4000 \mathrm{~V} \mathrm{DC})$. It is obvious that the design of highly reliable and relatively cheap traction drive for such power and highvoltage can be conducted only on the base of high-frequency power IGCT switches.

To get the high level of traction drive responsibility, it is necessary to specify very rigid requirements for the reliability of the power converter operation. Therefore it is thought to be reasonable to choose such principle of the work of the power circuit, which could provide the following:

(i) The power semiconductor devices will have the best working conditions, particularly during transient processes.

(ii) The control of the power high-voltage converter based on the rigid algorithm (independent from input voltage level, load value, etc.) must have a much higher fraction than control based on the flexible algorithm.

After careful consideration of existing decisions and methods, a power Pulse Width Modulation (PWM) high-voltage converter was chosen $[2,4-8]$. The open input of the converter makes the output characteristic rigid and, accordingly yields more simplifier control. The PWM technology for power high-voltage converter operating at constant frequency improves operation under no-load.

The first one is to provide normal operation for the semiconductor devices and could be solved by increasing of the components of defence circuits. The second problem is to minimize the losses in the protection circuit and should be solved by reducing the values of the parameters of defence circuits. The parameters of the defence circuits depend on choosing the power self-commutated devices. Therefore specific technical requirements and properties of
TABLE 1: Properties and parameters of power high-voltage semiconductor devices.

\begin{tabular}{lcccc}
\hline Ratings & GTO & IGCT & ETO & IGBT \\
& $3000 \mathrm{~A}$ & $4000 \mathrm{~A}$ & $1000 \mathrm{~A}$ & $1200 \mathrm{~A}$ \\
& $6000 \mathrm{~V}$ & $4500 \mathrm{~V}$ & $4500 \mathrm{~V}$ & $3300 \mathrm{~V}$ \\
\hline$V_{\text {sat }}, \mathrm{V}$ & 1.7 & $\mathbf{1 . 4}$ & 2.6 & 2.4 \\
$E_{\text {off }}, \mathrm{J}$ & 1.20 & 1.08 & 0.96 & $\mathbf{0 . 7 2}$ \\
$E_{\text {on }}, \mathrm{J}$ & 0.12 & 0.11 & $\mathbf{0 . 1 0}$ & 0.12 \\
$W_{c}$ & High & Middle & Low & Low \\
\hline
\end{tabular}

the power semiconductor devices are considered [2, 6, 9-13]. Some of them are the following:

(i) High current (rms, average, peak, and surge) and voltage (peak repetitive, surge, and DC-continuous).

(ii) Low losses (conduction and switching).

(iii) High reliability (low random failures, high power and temperature cycling, and high blocking stability).

An important quality is improved robustness and low device coast.

By output current $\left(I_{\text {out }}=400 \mathrm{~A}\right)$ and supply voltage $\left(V_{s}=2000 \mathrm{~V}\right)$ properties parameters of power high-voltage semiconductor devices such as GTO (Gate Turn-off Thyristor), IGCT (Integrated Gate-Commutated Thyristor), ETO (Emitter Turn-off Thyristor), and IGBT (Insulated Gate Bipolar Transistor) are analyzed for Russian suburban train applicationand summarised in Table 1, where

$E_{\text {off }}$ and $E_{\text {on }}$ are turn-off and turn-on energy switching losses over one period;

$V_{\text {sat }}$ is voltage saturation of semiconductor switch;

$W_{c}$ is power consumption of control system.

The best parameters of considered power semiconductor devices are in bold font. According to the above-described requirements IGCT devices are selected for traction highvoltage converter of suburban trains.

As a result of the completed analysis and design procedures the original basic power circuit of the traction driver for Russian suburban train is created. Only last improvements in modern semiconductor technique have given possibilities to design and create this scheme in real conditions. This circuit can realize as well drive mode as a mode of dynamic break for train.

In Figure 1 the original basic power circuit for the drive mode that gives to train forces for movements is shown. Let us give a short description of functional blocks from this circuit:

A1: the fast circuit breaker executing a protection of all blocks from over current.

A2: the input filter decreasing an influence of the proposed power traction drive to network power supply.

$A 3$ and A4: power modules including two IGCT (VS1 and VS2) as a semiconductor switches. 


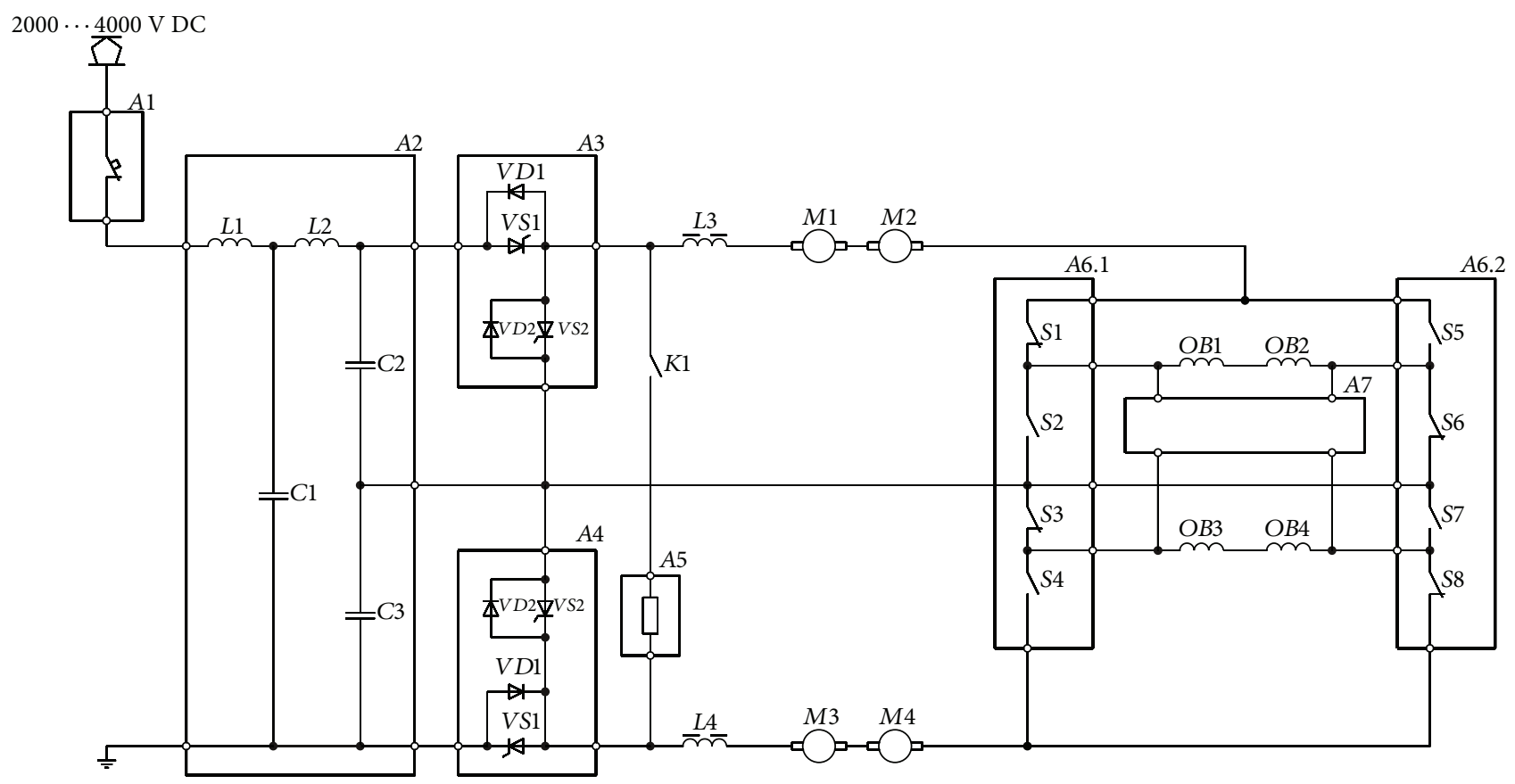

FIgURE 1: The basic power circuit for the drive mode.

A5: the block of brake resistors.

A6: the switches block executing the switching of the basic power circuit for the different modes.

A7: the auxiliary supply of excitation windings.

$K 1$ : the contactor which implements the brake mode by low speed of the train.

L3 and L4: chokes decreasing ripple of the motor current.

M1 ‥M4: brushed electric DC motors for $750 \mathrm{~V}$ DC every one.

$O B 1 \cdots O B 4$ : excitation windings of traction brushed electric DC motors $M 1 \cdots M 4$.

At the driver mode the control system of high-voltage converter commutes power semiconductor switches VS1 of modules $A 3$ and $A 4$ with using pulse width modulation (PWM). When power semiconductor switches VS1 of modules $A 3$ and $A 4$ are turned on (so-called pulse), then the power current flows as described in the following: the positive potential of the high-voltage supply $(2000 \cdots 4000 \mathrm{~V} D C)$, the fast circuit breaker $A 1$, the input filter $A 2$, the semiconductor switch VS1 of the module $A 3$, the choke $L 3$, traction motors $M 1$ and $M 2$, the switch $S 1$ of the block A6.1, excitation windings $O B 1$ and $O B 2$, switch $S 6$ of the block $A 6.2$ and $S 3$ of the block $A 6.1$, excitation windings $O B 3$ and $O B 4$, the switch $S 8$ of the block $A 6.2$, traction motors $M 4$ and $M 3$, the choke $L 4$, the semiconductor switch VS1 of the module A4, and the ground of the high-voltage supply.

When power semiconductor switches $V S 1$ of modules $A 3$ and $A 4$ are turned off (so-called pause), then chokes $L 3$ and $L 4$ and excitation windings $O B 1 \cdots O B 4$ become a voltage supply and the power current flows by the following two ways.
The first way: the positive potential EMF of the excitation winding $O B 2$, the switch $S 6$ of the block A6.2, the diode VD2 of the module $A 3$, the choke $L 3$, traction motors $M 1$ and $M 2$, the switch $S 1$ of the block $A 6.1$, and the negative potential EMF of the excitation winding $O B 1$.

The second way: the positive potential EMF of excitation winding $O B 4$, the switch $S 8$ of the block $A 6.2$, traction motors $M 4$ and $M 3$, the choke $L 4$, the diode VD2 of the module $A 4$, the switch $S 3$ of the block $A 6.1$, and the negative potential EMF of the excitation winding $O B 3$.

In order to increase or decrease the rotational frequency of traction brushed electric DC motors $M 1 \cdots M 4$, the control system of the high-voltage converter has to increases or decreases the width pulses semiconductor switches VS1 of modules $A 3$ and $A 4$. Thus the suburban train controls the speed.

If the suburban train has to move backwards, then the control system of high-voltage converter has to open switches $S 1, S 3, S 6$, and $S 8$ and has to close switches $S 2, S 4, S 5$, and $S 7$ of the blocks $A 6.1$ and $A 6.2$. In this case, when power semiconductor switches VS1 of modules $A 3$ and $A 4$ are turned on the power current flows in the following way: the positive potential of the high-voltage supply $(2000 \cdots 4000 \mathrm{~V} \mathrm{DC})$, the fast circuit breaker $A 1$, the input filter $A 2$, the semiconductor switch VS1 of module $A 3$, choke $L 3$, traction motors $M 1$ and $M 2$, switch $S 5$ of the block $A 6.2$, excitation windings $O B 2$ and $O B 1$, switches $S 2$ and $S 7$ of the blocks $A 6.1$ and $A 6.2$, excitation windings $O B 4$ and $O B 3$, the switch $S 4$ of the block $A 6.1$, traction motors $M 4$ and $M 3$, choke $L 4$, the power semiconductor VS1 of module $A 4$, and the ground of the high-voltage supply.

When power semiconductor switches VS1 of modules $A 3$ and $A 4$ are turned off, then the chokes $L 3$ and $L 4$ and 


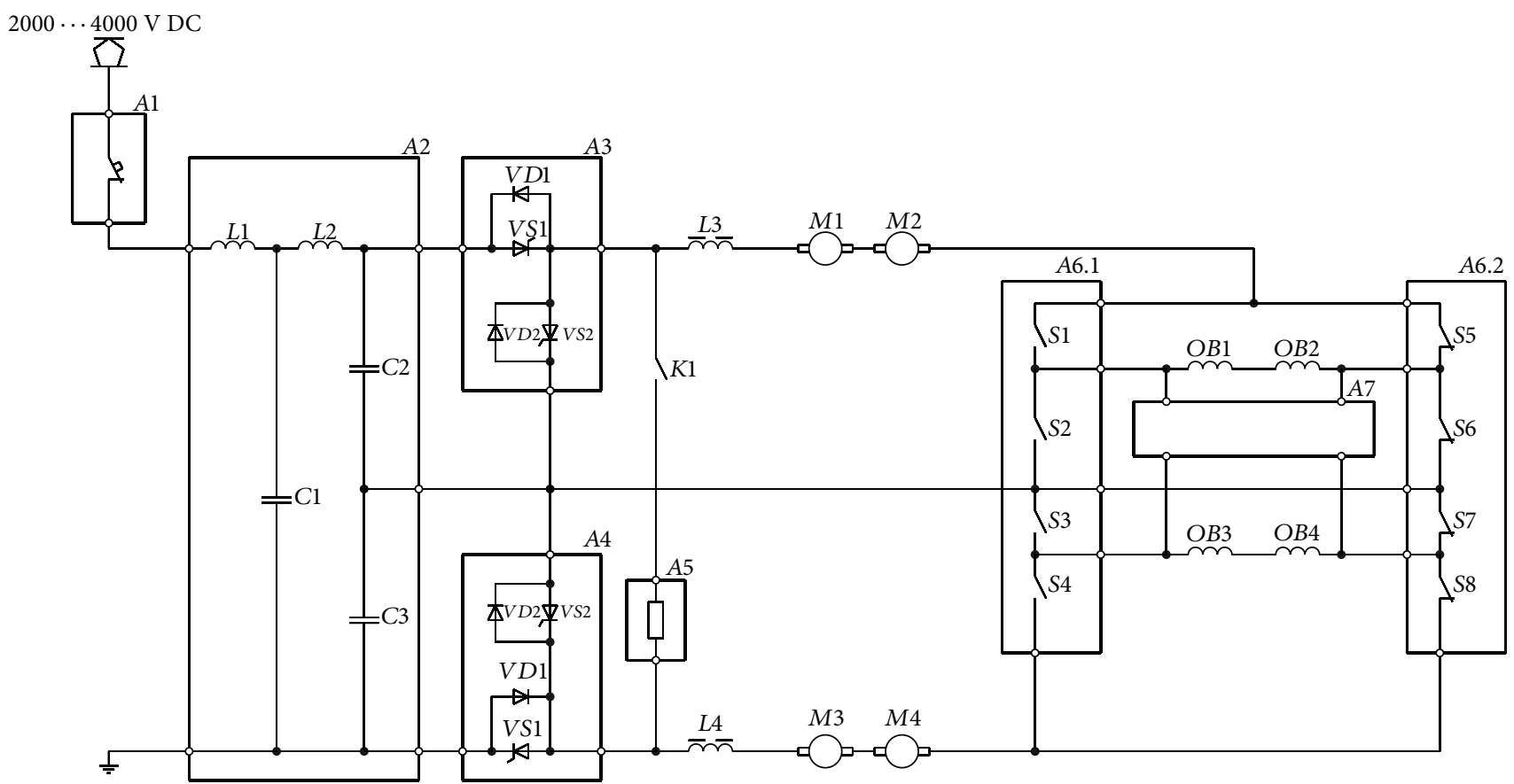

FIgURE 2: The basic power circuit for the brake mode.

excitation windings $O B 1 \cdots O B 4$ become a voltage supply and the power current flows by the following two ways.

The first way: the positive potential EMF of the excitation winding $O B 1$, switch $S 2$ of block $A 6.1$, diode VD2 of module $A 3$, choke $L 3$, traction motors $M 1$ and $M 2$, switch $S 5$ of block $A 6.2$, and the negative potential EMF of the excitation winding $O B 2$.

The second way: the positive potential EMF of the excitation winding $O B 3$, switch $S 4$ of block $A 6.1$, traction motors $M 4$ and $M 3$, choke $L 4$, diode VD2 of module $A 4$, switch $S 7$ of block $A 6.2$, and the negative potential EMF of the excitation winding $O B 4$.

In Figure 2 the basic power circuit for the brake mode that allows train to stop using the energy of traction brushed electric DC motor rotations without using the brake pads is shown.

If the suburban train has to stop, then the control system of high-voltage converter has to close switches $S 5 \cdots S 8$ of the blocks $A 6.2$ and has to open switches $S 1 \cdots S 4$ of the blocks A6.1.

It is clear that changing switches $S 1 \cdots S 8$ of the blocks $A 6.1$ and $A 6.2$ is one problem. The flowing power current evaluates $300 \cdots 400 \mathrm{~A}$ and there is a dangerous consequence of it. On this reason commute of switches of the blocks A6.1 and $A 6.2$ has to execute under zero current. In this case the EMF of power motors is equal to zero and brake forces of the train are equal to zero too. To eliminate the control system has to turn on the auxiliary supply $A 7$ of excitation windings $O B 1 \cdots O B 4$ that give initial current for train braking torque.

In this situation traction motors $M 1 \cdots M 4$ become a high-voltage supply of EMF.

At the brake mode the control system high-voltage converter commutes power semiconductor switches VS2 of modules $A 3$ and $A 4$ with using pulse width modulation (PWM). When power semiconductor switches VS2 of modules $A 3$ and $A 4$ are turned on, the power current flows by the following two ways.

The first way: the positive potential EMF of the traction motor $M 1$, choke $L 3$, the semiconductor switch VS2 of module $A 3$, switches $S 6$ and $S 5$ of block $A 6.2$, and the negative potential EMF of the traction motor M2.

The second way: the positive potential EMF of the traction motor $M 4$, switches $S 8$ and $S 7$ of block A6.2, the semiconductor switch VS2 of module A4, choke L4, and the negative potential EMF of the traction motor M3.

When power semiconductor switches VS2 of modules $A 3$ and $A 4$ are turned off, then the power current flows in the following way: the positive potential EMF of the traction motor $M 1$, choke $L 3$, diode VD1 of module $A 3$, the input filter $A 2$, the fast circuit breaker $A 1$, the positive potential of the high-voltage supply $(2000 \cdots 4000 \mathrm{~V} \mathrm{DC})$, the ground of the high-voltage supply, diode VD1 of the module $A 4$, choke $L 4$, traction motors $M 3$ and $M 4$, switches S8, S7, S6, and S5 of block A6.2, and traction motor M2.

By reducing the speed of the train the control system of high-voltage converter increases the pulse width of the semiconductor switches VS2 of modules $A 3$ and $A 4$. At low speed of the train the control system of high-voltage converter closes contactor $K 1$. When power semiconductor switches $V S 2$ of modules $A 3$ and $A 4$ are turned on, the power current flows by the following two ways.

The first way: the positive potential EMF of the traction motor $M 1$, choke $L 3$, semiconductor switch VS2 of module $A 3$, switches $S 6$ and $S 5$ of block A6.2, and the negative potential EMF of the traction motor M2. 


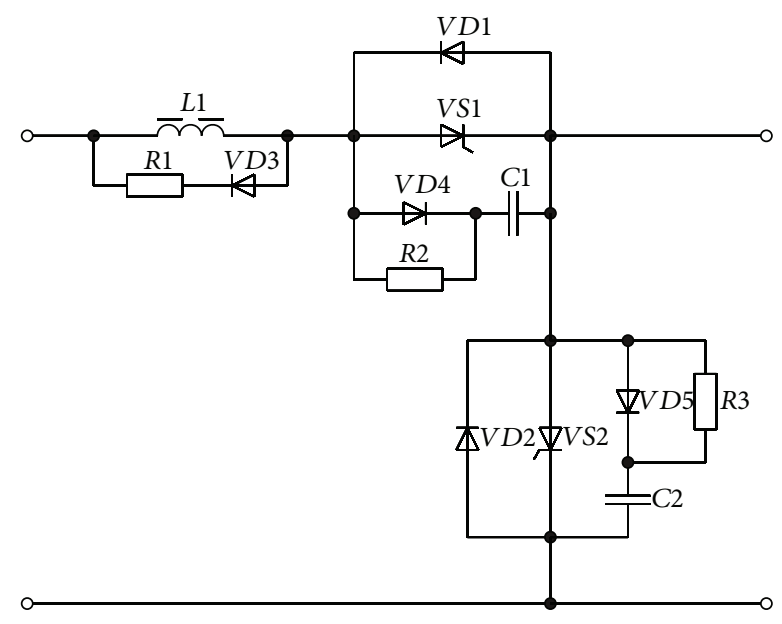

Figure 3: The basic power circuit of modules $A 3$ and $A 4$.

The second way: the positive potential EMF of the traction motor $M 4$, switches $S 8$ and $S 7$ of block $A 6.2$, the semiconductor switch VS2 of module $A 4$, choke $L 4$, and the negative potential EMF of the traction motor M4.

When power semiconductor switches VS2 of modules $A 3$ and $A 4$ are turned off, then the power current flows in the following way: the positive potential EMF of the traction motor $M 1$, choke $L 3$, diode $V D 1$ of module $A 3$, contactor $K 1$, block $A 6$ of brake resistors, diode $V D 1$ of module $A 4$, choke $L 4$, traction motors $M 3$ and $M 4$, switches $S 8, S 7, S 6$, and S5 of block $A 5$, and the traction motor $M 2$.

Thus the train stops without using the brake pads.

The important advantage of the proposed power circuit of the high-voltage converter is that power semiconductor switches VS1 and VS2 can be used with a $V_{\mathrm{DC}}=V_{s m} / 2$, where $V_{s m}$ is maximum voltage supply $(4000 \mathrm{~V} \mathrm{DC})$.

\section{Simulation and Design of Energy Efficient Snubber Circuits}

As a result of the analysis and design procedures the basic power circuit of modules $A 3$ and $A 4$ is selected and presented in Figure 3.

It contains two power semiconductor switches (VS1 and $V S 2$ ), two power diodes (VD1 and VD2), the clamping inductor $L 1$ with the diode $V D 3$ and the resistance $R 1$, snubber capacitors ( $C 1$ and $C 2$ ) with charging diodes (VD4 and $V D 5)$, and discharging, resistances ( $R 2$ and $R 3)$. Electrical components $L 1, C 1, C 2, V D 3 \cdots V D 5$ and $R 1 \cdots R 3$ form snubber circuits of semiconductor switches VS1 and VS2.

As power semiconductor switches VS1 and VS2 and power diodes VD1 and VD2 are selected and applied, the devices 5SHY35L4505 and 5SDF10H4502 were chosen as VS1 and VS2 and VD1 and VD2 correspondingly.

The clamping inductor $L 1$ limits the value of the instantaneous surge current $\left(I_{s}\right)$ and the rate of the rise of on-state surge current $\left(d I_{s} / d t\right)$ of the power semiconductor switches $V S 1$ in emergency regimes. The resistance $R 1$ limits the reverse voltage of the clamping inductor $L 1$, while dissipating

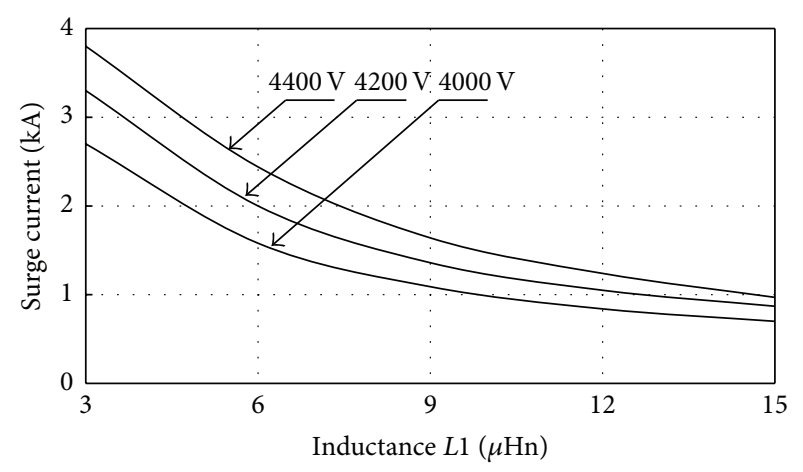

FIgURE 4: The surge current.

the clamping energy. The antiparallel diode VD3 provides the instantaneous clamping action, due to its fast forward characteristic.

The snubber capacitors $C 1$ accumulate a switching energy and, accordingly, limit the rate of rise of off-state voltage over power semiconductor switch VS1 for the drive mode. The charging diode VD4 is connected in series with snubber capacitor $C 1$ shunt discharging resistor $R 2$ in the forward direction. The discharging resistor $R 2$ limits the discharge current of the $C 1$ at turn-on of semiconductor switch VS1.

The snubber capacitors $C 2$ accumulate a switching energy and, accordingly, limit the rate of rise of off-state voltage over power semiconductor switch VS2 for the brace mode. The charging diode VD5 is connected in series with snubber capacitor $C 2$ shunt discharging resistor $R 3$ in the forward direction. The discharging resistor $R 3$ limits the discharge current of the C2 at turn-on of semiconductor switch VS2.

The accuracy of simulation results is achieved due to careful study of real transients in power semiconductor devices VS1 and VS2 (5SHY35L4505) and VD1 and VD2 (5SDF10H4502) for the following conditions: $V_{s}=2000 \mathrm{~V}$; $3000 \mathrm{~V}$ and $4000 \mathrm{~V} \mathrm{DC}$; $I_{\text {out }}=200 \mathrm{~A} ; 350 \mathrm{~A}$ and $400 \mathrm{~A}$. The CASPOC software for the simulation is used.

The comprehensive analysis of the transient is carried out for a wide range of different values of supply voltage, load, clamping inductor $L 1$, clamping resistance $R 1$, snubber capacitors ( $C 1$ and $C 2)$, and discharging resistances ( $R 2$ and $R 3$ ). It allows developing the simplified single-operating engineering algorithm for the estimation and selection of the proper defence circuit parameters with the initial constraints and lower power losses.

3.1. Design of the Clamping Inductor. The maximum values of the surge current $I_{s}$, the rate of the rise of on-state surge current $d I_{s} / d t$, and repetitive peak voltage $V_{m}$ on the off-state the power semiconductor switch VS1 are used as the initial data. These values are defined in accordance with a desired reliability of high-voltage converter.

The analysis of the transient shows that in case of a rise of the supply voltage and load current almost all parameters for the transient have got a tendency to change the conditions for the power semiconductor switch VS1 to the worse direction. Also the analysis shows that the maximum values of the surge current (Figure 4), the rate of the rise of on-state surge 
current, maximum nonrepetitive peak voltage, and the rate of rise off-state voltage $d V / d t$ over the power semiconductor switch VS1 in the emergency regimes are decreased when the inductor values of $L 1$ are increased. The maximum voltage $\left(V_{z}\right)$ on the turn-off power semiconductor switch $V S 1$ and maximum peak voltage $\left(V_{m}\right)$ on the off-state power semiconductor switch VS1 in normal operation are reduced slightly.

During its turn, the energy losses in the clamping resistance $R 1$ over one period are increased, when the inductor values of $L 1$ are increased. Accordingly it is limiting the values of the clamping inductor $L 1$.

For the proper synthesis of the energy efficient snubber circuits it is desirable to select the minimum possible inductor $L 1$ values and the following design strategy is recommended.

(1) The auxiliary variable is calculated:

$$
B=\frac{I_{s}-I_{m}}{T_{d}},
$$

where $T_{d}$ is value of minimum fall time.

(2) The maximum value of the $d I_{s} / d t$ and $B$ with its further equaling to $A$ is selected.

(3) The inductor $L 1$ value is calculated:

$$
L 1=\frac{V_{m}-\left(I_{s}-I_{m}\right) \cdot r}{2 \cdot A},
$$

where $r$ is minimum value of total resistance of the circuit in the emergency regimes.

The obtained values of the clamping inductance allow maintaining the minimum losses over one period in the clamping resistance $R 1$ in accordance with the requested value $B$ and task parameters $I_{s}$ and $I_{m}$ and $d I_{s} / d t$ power semiconductor switch VS1.

3.2. Design of the Clamping Resistance. The obtained value of the clamping inductance $L 1$ and the maximum values of the repetitive peak voltage $V_{m}$ on the off-state power semiconductor switch VS1 are used as the initial data.

The analysis of the transient shows that maximum peak voltage $V_{m}$ on the off-state semiconductor switch VS1 is decreased when the values of the clamping resistor $R 1$ are reduced (Figure 5). In its turn, the rate of the rise of current $d I_{v s} / d t$ of the semiconductor switch VS1 and the average current of the diode VD3 are increased when the values of the clamping resistor are reduced.

In order to select optimal clamping resistor the following design procedure is used.

(1) The auxiliary variables are calculated:

$$
\begin{aligned}
& R_{a}=\frac{V_{m}-V_{s m}}{4 \cdot I_{m}} ; \\
& R_{b}=\frac{V_{m s}-V_{s m}}{4 \cdot I_{s m}} ; \\
& R_{c}=\frac{Q}{L 1}-R_{v d}-R_{L 2},
\end{aligned}
$$

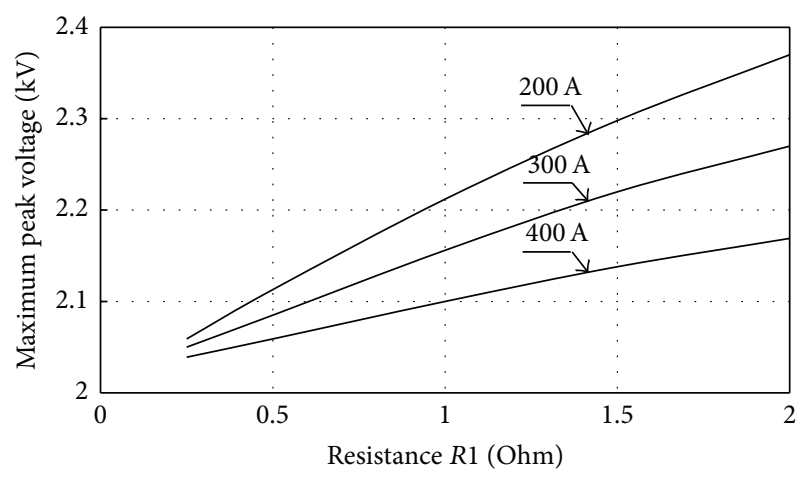

FIgURE 5: The maximum peak voltage.

where $Q$ is task time-constant of the clamping circuit; $R_{v d}$ and $R_{L 2}$ are values of the resistance of the diode $V D 3$ and clamping inductor $L 2$.

(2) The minimum value of the $R_{a}, R_{b}$, and $R_{c}$ with its further equaling to clamping resistor $R 1$ is selected.

3.3. Design of the Snubber Circuits. The parameters of the L2 and $R 1$ are used as the initial data for the simulation and further selection of the snubber capacitor $C 1$ and discharging resistor $R 2$. Additionally, the maximum values of the $V_{m}$ and $V_{m s}$ and the duration $\left(T_{c m}\right)$ and amplitude $\left(I_{c m}\right)$ of the discharge current are used as the initial data.

The analysis of the transient shows that the increase of snubber capacitor values leads to the power loss growth in the discharging resistors $R 2$ over one period. Therefore the low-loss energy regimes in the snubber circuits occur for the lowest values of the snubber capacitors $C 2$. During its turn, the increase of the snubber capacitor values leads to the growth of the transient duration. Also the analysis shows that the amplitude $I_{c}$ of discharge current is increased, but the duration $T_{c}$ is decreased, when the values of the resistor $R 2$ are decreased.

For selecting the minimum possible capacitors values the following design strategy is recommended.

(1) The auxiliary variable is calculated:

$$
C_{m}=\frac{2 \cdot I_{s m} \cdot T_{c m}}{V_{m s}-V_{s m}} .
$$

(2) The auxiliary variables are calculated:

$$
\begin{aligned}
R_{m} & =\frac{T_{c m}}{2 \cdot C_{m}}-R_{v s}, \\
R_{c m} & =\frac{V_{s m}}{I_{c m}}-R_{v s},
\end{aligned}
$$

where $R_{v s}$ is value of the resistance of the power semiconductor switch VS1.

(3) The optimum of the $R_{m}$ and $R_{c m}$ with its further equaling to $R 2$ is selected. 


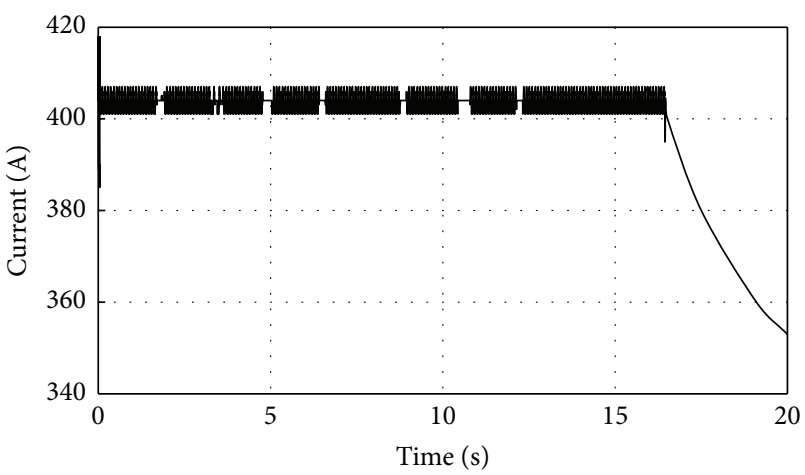

FiguRE 6: The current waveform.

(4) Dependencies of the maximum values of the instantaneous surge current $I_{s}$ and the rate of the rise of on-state surge current $d I_{s} / d t$ of the switch VS1 in the emergency regimes are simulated. The value of the clamping inductance $L 1$ are defined according to the requirements $I_{s m}$ and $d I_{s m} / d t$ and results of the CASPOC simulation.

(5) The dependencies of the maximum values of the instantaneous repetitive peak voltage on the offstate power semiconductor switch VS1 are simulated. Value of the clamping resistor $R 1$, snubber capacitor $C 2$, and snubber resistor $R 2$ are defined according to the requirements $V_{m}$ and $V_{m s}$ and results of the CASPOC simulation.

The values of snubber capacitor $C 3$ and snubber resistor $R 3$ of the power semiconductor switch VS2 are determined in the same way, taking into account inductance chokes $L 3$ and $L 4$.

The obtained values of the defence circuits allow maintaining the minimum losses over one period in the resistor $R 1$ and snubber resistors $R 2$ and $R 3$ in accordance with the requirement of the task parameters $V_{m}, V_{m s}, I_{s m}, d I_{s m} / d t$, and $I_{c m}$.

\section{Computer Simulation}

Transients, quasi-steady-states and emergency mode of the operation are passed using CASPOC software. The comprehensive analysis of the transient is considered out for a wide range of the supply voltage and parameters variation of the load, clamping inductor, clamping resistance, snubber capacitors and discharging resistances. The current and voltage curves of the proposed high-voltage converter are received and analyzed as a result of computer simulation. For example, the simulation results of the current waveform $(i)$ of the power semiconductor switch VS2 are shown in Figure 6 for starting movement of the train at the supply voltage $3000 \mathrm{~V}$ and limiting current $400 \mathrm{~A}$.

As the simulation result, the suburban train speed ( $v$, $\mathrm{km} / \mathrm{h}$ ) dependence as the functions of the way $(L, \mathrm{~m})$ is shown in Figure 7.

Also CASPOC was used for examination of the interference of proposed high-voltage converter into the central
TABLE 2: Parameters of elements of snubber circuits.

\begin{tabular}{lccccc}
\hline$L 1$ & $R 1$ & $C 1$ & $R 2$ & $C 2$ & $R 3$ \\
\hline $0.9 \mathrm{mH}$ & $9.1 \mathrm{Om}$ & $0.03 \mathrm{mF}$ & $91 \mathrm{Om}$ & $0.02 \mathrm{mF}$ & $120 \mathrm{Om}$ \\
\hline
\end{tabular}

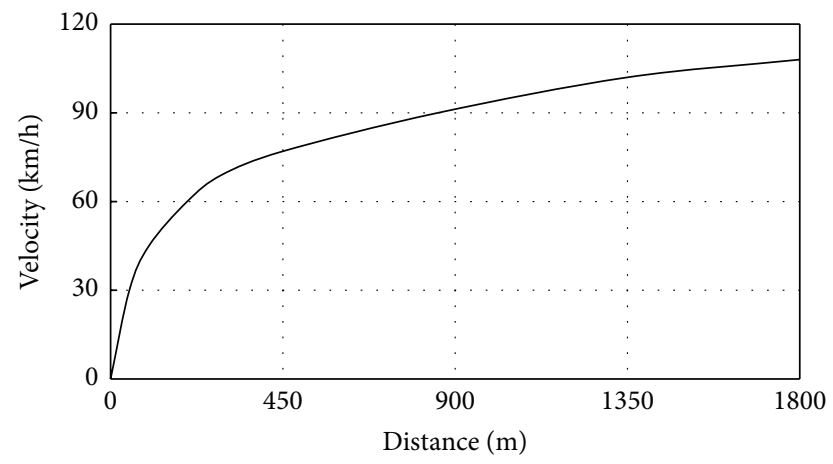

FIGURE 7: The speed waveform of the train.

railways emergency system and wire communications. Computer simulation of electromagnetic processes show that the maximal amplitudes of the input current harmonic components appear at the maximal permissible loads (400 A) and the input voltage $(4000 \mathrm{~V})$. The maximal values of the harmonic component amplitudes (equal to $77 \mathrm{~mA}, 2790 \mathrm{~Hz}$ ) are not exceeding the permissible values.

As a result of the comprehensive analysis the optimum parameters of elements of snubber circuits of semiconductor switches VS1 and VS2 are given in Table 2.

\section{Sample Description}

The skilled sample of the power module for Russian suburban trains is designed. In the design sample was decided to be applied to power fast IGCT devises 5SHY35L4505 (as semiconductor switches VS1 and VS2) and power fast diodes 5SDF10H4502 (as diodes VD1 and VD2) to increase the working frequency of the proposed high-voltage converter and, accordingly, to decrease the total weight and sizes of the power module. Chosen power IGCT has turn-off time at most $2 \mu$ s with repetitive peak voltage in the off state $4500 \mathrm{~V}$, critical rate of voltage rise in the off state $1000 \mathrm{~V} / \mu \mathrm{s}$, and critical rate of current rise in the on state $500 \mathrm{~A} / \mu \mathrm{s}$. Chosen power diodes with repetitive pulse reverse voltage $4500 \mathrm{~V}$ and forward current $2000 \mathrm{~A}$ (rms) have reverse recovery time at most $1 \mu \mathrm{s}$.

Clamping inductors $L 1$ of the power module are chosen to be air-core. This allowed their normal functioning in case of emergency modes of the considered high-voltage converter, when the short-time shock current exceeds $2 \div$ $3 \mathrm{kA}$. This value greatly exceeds nominal current and makes the application of iron-core clamping inductor inefficient. External diameter of the clamping inductor $L 1$ of the power module is $70 \mathrm{~mm}$, internal diameter is $50 \mathrm{~mm}$, and height is $50 \mathrm{~mm}$.

The design power module of the proposed converter is shown in Figure 8. It has forced oil cooling. Its dimensions are 


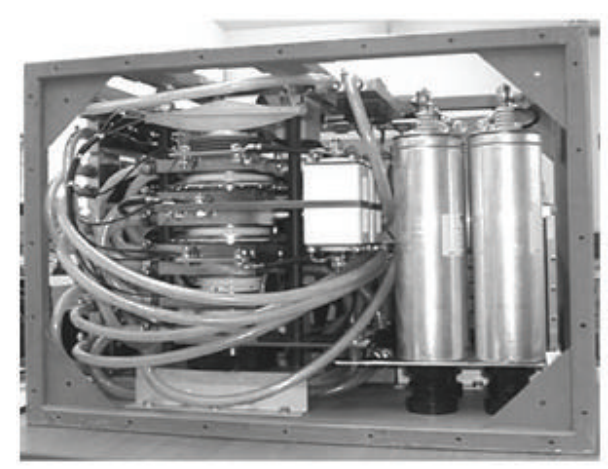

Figure 8: The power module.

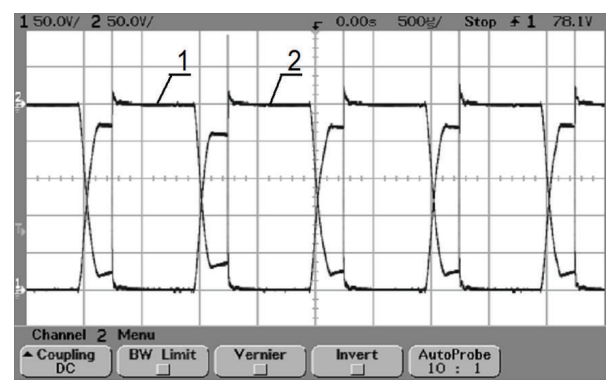

FIGURE 9: The voltage waveforms of the power switches VS1 (curve 1) and VS2 (curve 2).

$570 \mathrm{~mm}, 730 \mathrm{~mm}$, and $550 \mathrm{~mm}$ and weight does not exceed $90 \mathrm{~kg}$.

Complete tests of the power module are conducted in the high-voltage experimental laboratory for checking the accuracy of the mathematical model. As an example, the test results of the voltage waveforms of the power switches VS1 (curve 1) and VS2 (curve 2) are presented in Figure 9 at the supply voltage $4000 \mathrm{~V}$ and limit current $200 \mathrm{~A}$.

The surface temperatures of electrical components of the power module are also measured. The maximum surface temperature excess over the ambient temperature is fixed for the clamping inductor $L 1$. It is equal to $77.5^{\circ} \mathrm{C}$. The power semiconductor switches VS1 and VS2 have a maximum temperature excess of $71^{\circ} \mathrm{C}$.

\section{Conclusion}

As a result of the completed analysis and design procedures the original high-voltage converter of the traction driver for Russian suburban train is proposed. The authors developed the detailed algorithm for the calculation and selection of the elements of the low-loss snubber circuits for considered converter. This algorithm is used during the preliminary design stage of the traction converters with nominal output power $1200 \mathrm{~kW}$ (maximum power $2100 \mathrm{~kW}$ ) at the unstable input voltage $2000 \cdots 4000 \mathrm{~V}$ DC. It allowed reducing the power losses in the snubber circuits on $23 \%$. For this reason the traction driver should incorporate the features of welldesigned snubber circuits to insure power converter device protection regardless of wide range of either supply or load conditions.

The important advantage of the proposed power circuit of the high-voltage converter is that power semiconductor switches VS1 and VS2 can be used with a $V_{\mathrm{DC}}=V_{s m} / 2$, where $V_{s m}$ is maximum voltage supply ( $\left.4000 \mathrm{~V} \mathrm{DC}\right)$.

Extensive tests of the designed converter conducted in the high-voltage laboratory demonstrated the high accuracy of the used software, and the correctness of the chosen basic power elements. The complex tests have shown that the considered high-voltage converter operates stably at steadystate conditions over a whole range of the input voltages and permissible loads (including their discrete variations) and at the starting mode and turn-off of the loads.

The presented results are very interesting for the designers of power high-voltage converters and traction drive.

\section{Competing Interests}

The authors declare that there are no competing interests regarding the publication of this paper.

\section{References}

[1] V. K. Milovanov and S. I. Volsky, "The "Sputnik" electric train for the new transport system on the Moscow-Mytishchi line," Rail International, vol. 34, pp. 20-27, 2003.

[2] D. O. Neacsu, Switching Power Converters: Medium and High Power, 2nd edition, 2013.

[3] S. I. Volskiy, Y. Y. Skorokhod, and V. V. Shergin, "The analysis and simulation of power circuits for high voltage converter," in Proceedings of the CES/IEEE 5th International Power Electronics and Motion Control Conference (IPEMC '06), pp. 1-5, Shanghai, China, August 2006.

[4] R. Severns, Snubber Circuits for Power Electronics, 2008.

[5] S. I. Vol'skij, G. A. Dubenskij, and O. A. Gusarov, "A development of high-voltage high-frequency static converters," Elektrichestvo, no. 5, pp. 30-40, 2002.

[6] N. Kularatna, DC Power Supplies: Power Management and Surge Protection for Power Electronic Systems, CRC Press, London, UK, 2011.

[7] D. O. Neacsu, "Optimization of double-sampled PWM used within power supplies," in Proceedings of the 39th Annual Conference of the IEEE Industrial Electronics Society (IECON '13), pp. 1118-1123, Vienna, Austria, November 2013.

[8] Y. Skorokhod, S. Volsky, N. Antushev, and N. Volskiy, "Power supply source for the continental shelf bottom exploration system," in Proceedings of the nternational Exhibition and Conference for Power Electronics, Intelligent Motion, Renewable Energy and Energy Management (PCIM '14), pp. 1-8, Nuremberg, Germany, May 2014.

[9] J. Lutz, H. Schlangenotto, U. Scheuermann, and R. Doncker, Semiconductor Power Devices, Springer, Berlin, Germany, 2011.

[10] T. Clausen and B. Backlund, "High power IGCT switchesstate-of-the-art and future," Power Electronics Europe, no. 3, pp. 30-34, 2011.

[11] P. K. Steimer, "IGCT-a new emerging technology for high power, low cost inverters," IEEE Industry Applications Magazine, vol. 2, no. 4, pp. 12-18, 2013. 
[12] http://www.mitsubishielectric.com/news/2015/.

[13] K. Hatori, "The next generation $6.5 \mathrm{kV}$ IGBT module with high robustness," in Proceedings of the PCIM Europe Conference, Nuremberg, Germany, 2014. 


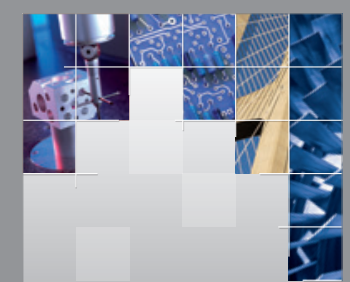

\section{Enfincering}
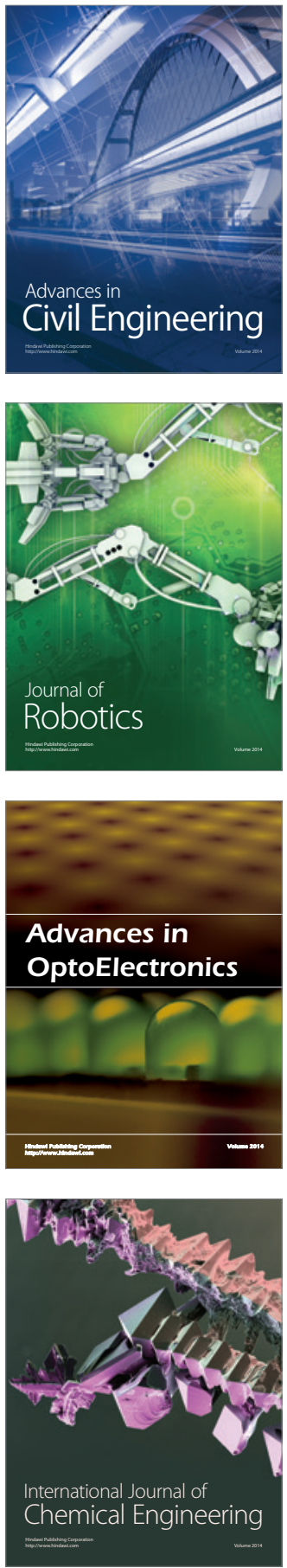

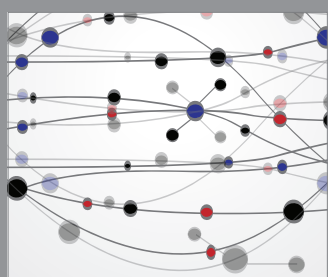

The Scientific World Journal

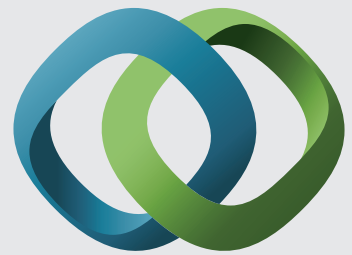

\section{Hindawi}

Submit your manuscripts at

http://www.hindawi.com
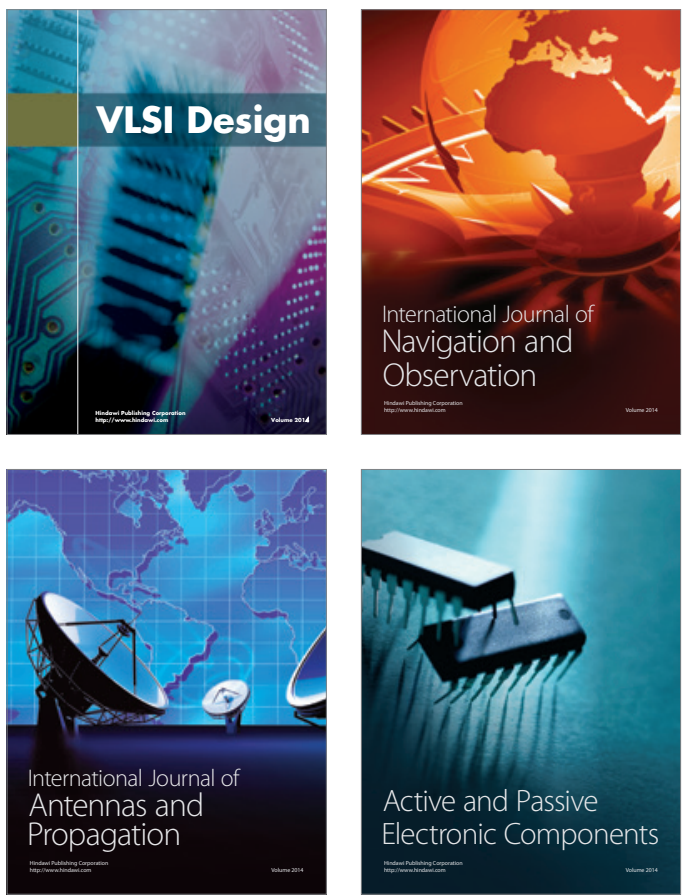
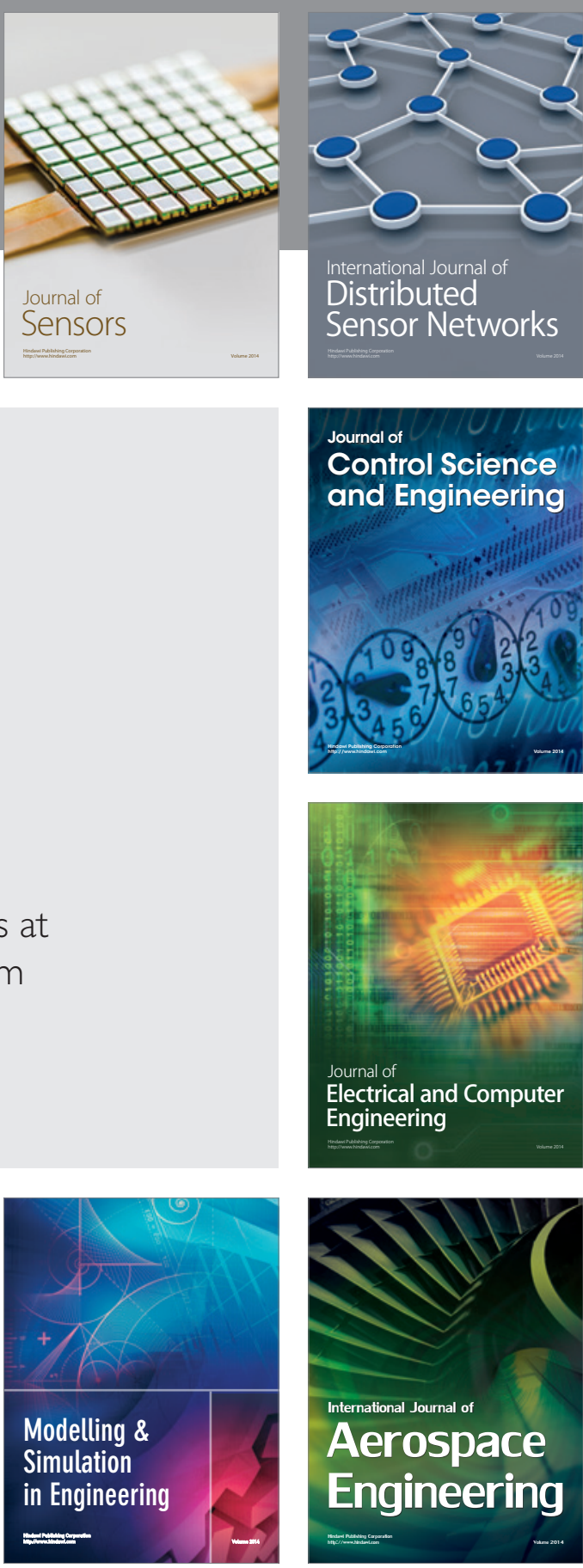

International Journal of

Distributed

Sensor Networks

Journal of

Control Science

and Engineering
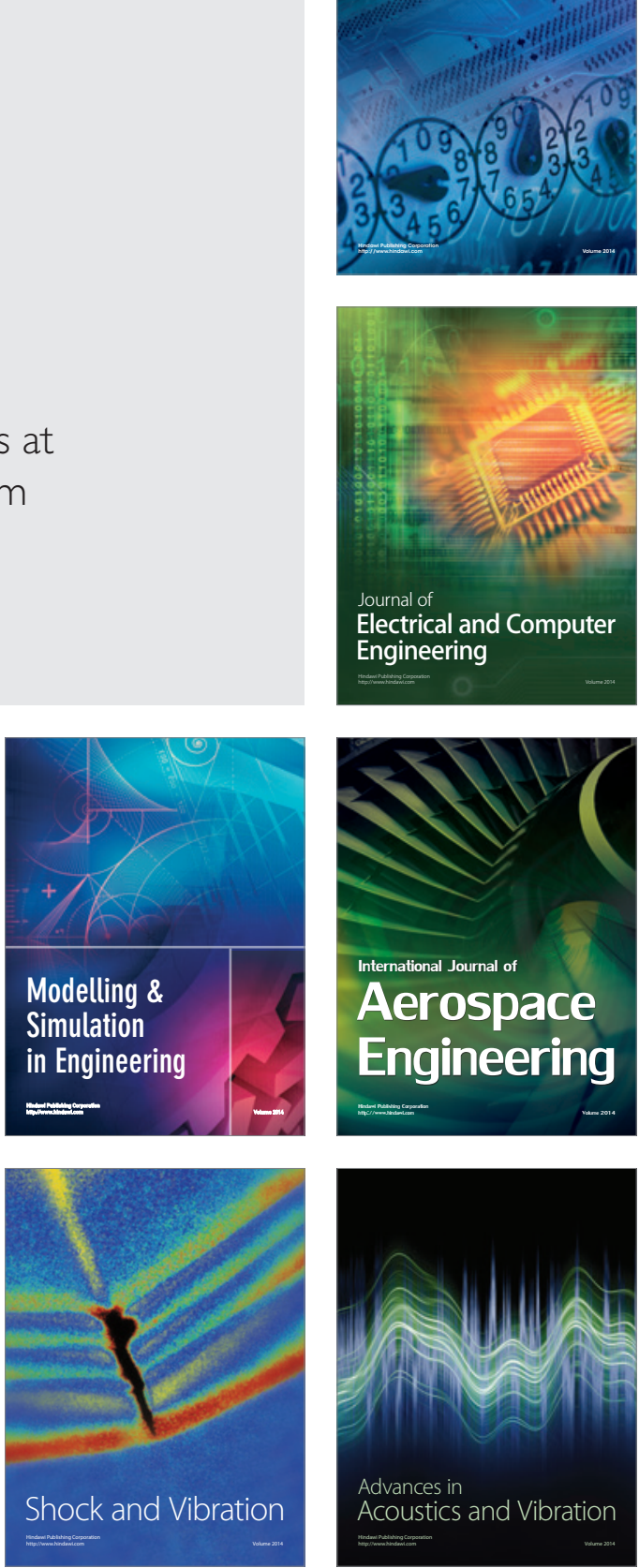